\title{
Produção de Histórias em Quadrinhos na abordagem interdisciplinar de Biologia e Química
}

Victor João da Rocha Maia Santos, Colégio de Aplicação, Universidade Federal do Rio Grande do Sul, victor.jrms@gmail.com

Fernanda Britto da Silva, Colégio de Aplicação, Universidade Federal do Rio Grande do Sul, febritto@gmail.com

Monica Fagundes Acioli, Colégio de Aplicação, Universidade Federal do Rio Grande do Sul, monifacioli@yahoo.com.br

Comics Development in the interdisciplinary approach of Biology and Chemistry Abstract. Technologies to generate and share information has advanced in education by creating new spaces for knowledge. With different tools, digital communication and learning can be made more attractive to the students. Comic's construction can be one of them, as it involves creativity in the production of scenarios and characters that must be linked to texts, promoting relationship with the studied object. In a biology and chemistry shared class, concepts and relations between oil and environment polution were worked and comics were constructed by the students using the UCA laptop, to stimulate creativity in the development of knowledge about that classes.

Keywords: Comics, UCA laptop.

Resumo. O uso das tecnologias digitais tem avançado na educação criando novos espaços de construção e troca de conhecimentos sendo que a aprendizagem pode tornarse mais atrativa aos estudantes, na medida em que o educador se utilize das ferramentas adequadas. A construção de Histórias em Quadrinhos (HQs) pode ser uma delas, já que envolve a criatividade na produção de cenários e personagens que devem ser associados aos textos, promovendo relação com o objeto estudado. Em aula compartilhada de Biologia e Química, trabalharam-se conceitos e relações entre óleos, gorduras e meio ambiente e promoveu-se a construção de HQs utilizando o UCA, para estimular a criatividade no desenvolvimento do conhecimento.

Palavras-chave: Histórias em quadrinhos, UCA, TICs.

\section{Introdução}

\section{Tecnologias da Informação e Comunicação (TICs)}

Em um mundo cada dia mais globalizado, é fácil entender a importância das tecnologias disponíveis para gerar e compartilhar informações. Essas ferramentas, chamadas "Tecnologias da Informação e Comunicação" - TICs oportunizam ampla socialização entre os indivíduos, criando novos espaços de construção e troca de conhecimentos, aproximando as pessoas e promovendo um avanço na comunicação.

No âmbito educacional, há muito se percebe a influência destas novas metodologias de contato com o mundo na aquisição de informaç̃os diversas pelos estudantes. Neste sentido, entende-se que as várias inovações tecnológicas podem auxiliar na promoção de mudanças educacionais. Entretanto, estas mudanças só podem realmente ser efetivas na medida em que os educadores se apropriem delas (Neto et. al., 2011), promovendo, conduzindo e estimulando seu uso, criando assim possibilidades para a construção do conhecimento e da aprendizagem. Logo, cabe ao professor, o papel de ajudar o aluno a interpretar, relacionar e contextualizar as informações ao cotidiano (Moran, 2000). Neste contexto, em todo o mundo, o computador faz-se uma importante 
ferramenta, pois ajuda na orientação da aprendizagem e auxilia na busca de respostas que ajudem o sujeito na elaboração do conhecimento (Pais, 2002).

No Brasil, desde 2005, o governo vem implementando o programa Um Computador por Aluno - UCA (Miranda et. al. 2011), que traz a proposta de fornecer na modalidade 1:1 computadores portáteis de baixo custo a alunos e professores da educação básica pública, como um mecanismo de inclusão social e digital para esses sujeitos. Neste sentido pode-se entender que educadores e educandos participantes deste programa têm a oportunidade de aprender criando e estimulando a autonomia e a colaboração, o que são bases da implantação do programa.

Com a crescente inclusão digital nos espaços escolares, outro aspecto a ser considerado é a interdisciplinaridade, pois a realidade é interdisciplinar e dinâmica (Demo, 2001) e o livre e rápido acesso às informações, proporcionado pelas novas tecnologias evidenciam cada vez mais esse fato que não pode ser ignorado. Segundo Wilson (2001), ainda que os saberes adquiridos em áreas específicas do conhecimento tenham seu valor, a especialização (separação por disciplinas) é um artifício metodológico, uma estratégia simplista que não reflete a realidade.

Assim, as atividades em sala de aula precisam contemplar as Tecnologias de Informação e Comunicação, aliadas à interdisciplinaridade, para tornarem-se ainda mais efetivas e contextualizadas no mundo em que os educandos estão inseridos.

\section{Histórias em Quadrinhos (HQs)}

As HQs, assim como outras TICs, podem ser utilizadas como meio para facilitar a compreensão de assuntos geralmente difíceis de se entender pela população em geral. Pensando dessa maneira, muito material de divulgação científica tem sido produzido especialmente para estudantes (de todos os níveis de ensino, desde de que já tenham sido alfabetizados), através das Histórias em Quadrinhos, contendo material de cunho científico e tecnológico (Cabello, Rocque e Souza, 2010).

Se considerarmos que boa parte da sociedade brasileira é ociosa para a leitura em geral (Instituto Pró-Livro 2012), visto que a maior parte da sociedade brasileira prefere assistir a filme dublados do que legendados (Giron, 2012), percebemos que o campo para a divulgação e alfabetização científica por intermédio das Histórias em Quadrinhos é uma maneira possivelmente útil e eficaz, porque permite ao leitor não somente imaginar, mas também participar da trama, mesmo que de forma passiva, já que acredita-se que a leitura de HQs pode despertar o gosto pela leitura.

As Histórias em Quadrinhos são a chave para a leitura mais formal. O contato de crianças e jovens com algum tipo de HQ torna-se um motivador primário para preparálos para o prazer de qualquer tipo de leitura e a enfrentarem textos didáticos, literários e informativos (Santos, 2003).

Vale ressaltar que nos Parâmetros Curriculares Nacionais para o Ensino Médio (PCNEM/00), na parte II, referente a Linguagens, Códigos e suas Tecnologias, há a seguinte afirmação: "As novas tecnologias da comunicação e da informação permeiam o cotidiano, independente do espaço físico, e criam necessidades de vida e convivência que precisam ser analisadas no espaço escolar. A televisão, o rádio, a informática, entre outras, fizeram com que os homens se aproximassem por imagens e sons de mundos antes inimagináveis." Entretanto, foi somente em 2007 que o governo Federal incluiu no Programa Nacional Biblioteca da Escola (PNBE), que funciona desde 1997, a utilização das HQs como instrumento de aprendizagem. A alegação do governo seria de que "o elemento visual é um atrativo a mais para incentivar a leitura nos alunos" (Ramos, 2006). Infelizmente, esse tipo de TIC chega com enorme atraso na educação brasileira. 
Com o melhoramento da internet e de softwares para computador, os quadrinhos ganharam espaço no mundo digital, facilitando assim, a produção e divulgação das HQs por parte de pessoas que possuem dificuldade na elaboração de desenhos. Navegando pela internet podemos obter uma quantidade enorme de sites que produzem quadrinhos. Entre esses, existe o Pixton, com versão em português, o qual difere dos demais programas por possuir personagens (avatares) modelados em 3D que facilitam ao usuário movimentá-lo de várias maneiras nos quadrinhos, além de possibilitar a personalização do avatar e a adição de novos cenários e objetos, que possam não constar na biblioteca desse software.

Faz-se necessário ressaltar que pesquisas utilizando HQs, principalmente no ensino de ciências e em particular no ensino médio, são um campo ainda muito pouco explorado (Cabello, Rocque e Souza 2010).

De acordo com a pesquisa realizada por Claúdia Kamel, do Departamento de Inovações Educacionais do Instituto Oswaldo Cruz (IOC), as HQs, deixaram de ser consideradas subliteratura, para ascenderem como instrumentos importantes para a divulgação científica no ensino de ciências. Para a pesquisadora, a leitura de uma história em quadrinhos aciona pelo menos, 20 competências cognitivas, entre elas, perspectiva e profundidade. (Castilhos, 2008).

Os quadrinhos são um tipo de arte sequencial e por esse motivo se tornam um instrumento muito importante e que prestam para muitos fins na área educacional. Mesmo sabendo-se que as HQs são úteis no ensino-aprendizagem das ciências da natureza, no Ensino Médio, o número de pesquisas ainda é muito baixo e sua pouca utilização neste contexto, pode estar relacionada a vários fatores, entre os quais podemos destacar a ideia de que os quadrinhos devem ser utilizados somente para crianças na educação infantil para aprender a ler ou melhorar a leitura.

Por representarem um meio de comunicação de vasto consumo e com conteúdo, até os dias de hoje, majoritariamente direcionado às crianças e jovens, as HQs cedo se tornaram objeto de restrição, condenadas por muitos pais e professores no mundo inteiro.(...)Pais e mestres desconfiavam das aventuras fantasiosas das páginas multicoloridas das HQs, supondo que elas poderiam afastar crianças e jovens de leituras "mais profundas", desviando-os assim de um amadurecimento "sadio e responsável". Daí, a entrada dos quadrinhos em sala de aula encontrou severas restrições, acabando por serem banidos, muitas vezes de forma até violenta, do ambiente escolar. Aos poucos, tais restrições foram atenuadas e extinguidas, mas não de forma tranquila, sendo na verdade resultado de uma longa e árdua jornada. (Vergueiro, 2004, p.8)

Entretanto, há um número significativo de pesquisas que utilizam HQs na educação infantil e no ensino fundamental, principalmente, nas áreas Linguagem e Humanidades. Há destaques para o trabalho do professor e pesquisador Francisco Caruso (Professor Adjunto da UERJ e Pesquisador Titular do CBPF - Centro Brasileiro de Pesquisas Físicas), que é um dos representantes da área de Ciências (ensino de Física) que utiliza e produz Histórias em Quadrinhos específicas para o ensinoaprendizagem e como meio de divulgação científica em ciências da natureza. 
4

Devido ao pouco tempo de utilização de HQs em ensino de ciências, como forma de divulgação científica no ensino básico, como citado, nota-se uma carência de se conhecer uma forma básica de "como fazer", para que os professores possam utilizar essa ferramenta no ensino.

(...)a ausência de propostas para uma metodologia que envolva quadrinhos e conteúdos científicos abre uma lacuna a ser preenchida por pesquisadores e professores que desejam se aventurar em práticas que fomentem propostas plausíveis de aproveitamento deste material para a divulgação e educação científica (Pizarro, 2009).

Talvez, o motivo principal da dificuldade da utilização de HQs na educação se deva ao fato de que esse tipo de publicação não tenha origem acadêmica, mas do meio de mídia de massa, cujo principal enfoque é apenas o entretenimento. Essa mídia (como muitas outras) passou a ser apropriada pela área da educação, para estudos acadêmicos, de forma a ser, difundida para outras formas do ensino, do básico ao superior, e como forma de divulgação científica e de informação por outros tipos de instituições, tais como sindicatos, igrejas, indústrias, comércio, entre outros.

Possivelmente, se a academia "desse as mãos" às empresas de entretenimento, para saber como se faz este tipo de mídia, provavelmente, a mesma seria mais difundida e mais estilizada, sendo bem mais aproveitada como forma de divulgação científica, desde as séries iniciais até o ensino mais avançado.

\section{Metodologia}

Esta pesquisa foi desenvolvida com alunos da terceira série do ensino médio de um colégio da Rede Pública de ensino de Porto Alegre (RS) em períodos compartilhados entre as disciplinas de Biologia e Química. A atividade foi realizada com 48 alunos no primeiro semestre do ano de 2012 abordando-se o tema "Reciclagem de óleo" onde foram discutidas questões ambientais contemplando as duas áreas do conhecimento.

O trabalho foi desenvolvido em duas etapas, sendo a primeira realizada através de aulas expositivas e práticas em laboratório, totalizando 13h/aula. Os pontos abordados nas aulas expositivas, utilizando recursos de multimídia, foram: estrutura química de óleos e gorduras, importância biológica dos lipídios, impactos ambientais causados por descarte inadequado de óleo de cozinha usado e por derramamento de petróleo. Em laboratório, verificamos a dispersão da partícula de óleo em água bem como utilizamos óleo de cozinha usado para a produção de sabão líquido.

A segunda etapa consistiu de $6 \mathrm{~h} /$ aula onde se desenvolveu a elaboração das Histórias em Quadrinhos. Para tanto, a turma foi organizada em grupos de cinco a seis alunos os quais utilizaram os computadores do projeto UCA conectados à internet. $\mathrm{O}$ programa escolhido para esta atividade foi o Pixton (para Escolas), adquirido pela escola por um período de dois meses. Optou-se pela versão full por esta disponibilizar um maior número de recursos para a confecção das HQs. Além disso, o programa apresenta interface intuitiva, o que facilita o seu uso pelos alunos. Foram fornecidos aos alunos os passos básicos para a produção do trabalho, que foram: 1. Escrever um roteiro da história; 2. Descrever os personagens e cenários; 3. Fazer um esboço da distribuição dos quadros; 4. Diagramação; 5. Finalização; 6. Publicação. 
Durante as aulas, os alunos debateram sobre os temas propostos para as HQs no intuito de escrever uma história que contemplasse seus públicos-alvo. Cada grupo de alunos escreveu sua história direcionada às diferentes modalidades do Colégio - Ensino Regular e Educação de Jovens e Adultos - e diferentes níveis de ensino - Ensino Fundamental (séries iniciais e finais) e Ensino Médio, resultando em cinco diferentes HQs.

Uma análise de autoavaliação foi feita com os alunos através da aplicação de um questionário com questões em que eles mensuravam o desenvolvimento da atividade. $\mathrm{O}$ questionário constava de 4 perguntas onde os mesmos avaliavam em uma escala de 1 a 5 , sendo 1 o valor mais baixo e 5 o valor mais alto, questões relacionadas à produtividade, satisfação e facilidade na aprendizagem através do uso da ferramenta digital, além de uma quinta questão onde os alunos poderiam expressar sugestões e comentários. As respostas foram tratadas através de análise de conteúdo, sendo categorizadas, descritas e interpretadas, de acordo com Moraes (1999).

\section{Resultados e Discussão}

Participaram da atividade 48 alunos. Vinte e oito concluíram a construção das Histórias em Quadrinhos (Figura 1) e, com base nos critérios adotados para a avaliação, entendemos que estes estudantes obtiveram um rendimento adequado ao que foi proposto.
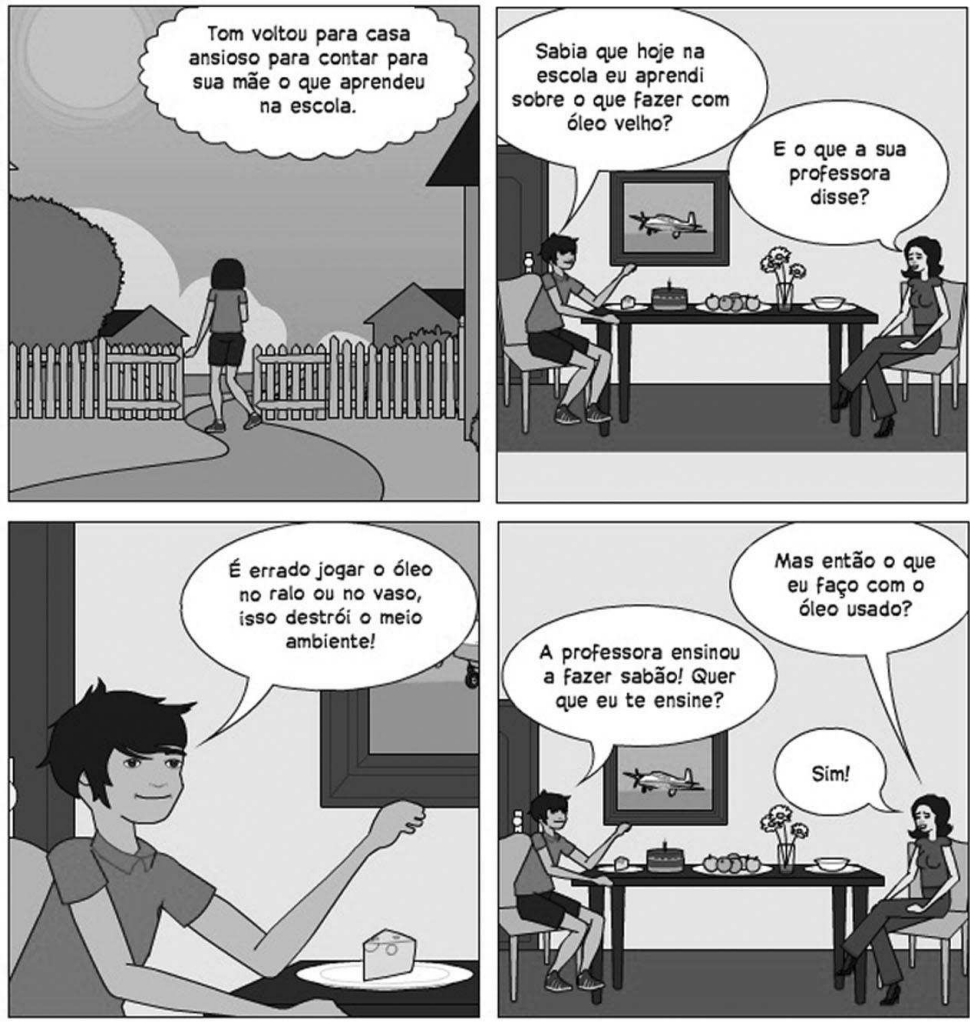

Figura 1 - Parte de HQ produzida por alunos do $3^{\circ}$ do Ensino Médio do Colégio de Aplicação da UFRGS utilizando o Pixton.

A análise de conteúdos, através da categorização por análise sintática, evidenciou algumas opiniões dos alunos, nas quais, a maioria se manifestou 
positivamente quanto à construção das HQs. Do total de alunos, 32 expressaram-se positivamente em relação ao uso da ferramenta, entendendo que seria uma proposta importante de ser desenvolvida em aula.

Os alunos que não gostaram de desenvolver a atividade (29), justificaram suas percepções de diversas formas, entre elas, podemos citar: "atividade é desnecessária para a etapa escolar em que foi aplicada"; "a atividade usou mais tempo do que precisava"; "o assunto não motivou". Entretanto, aqueles que gostaram da atividade, justificaram suas respostas alegando que a mesma auxiliou na aquisição do conhecimento em relação ao tema abordado.

Os alunos que concluíram as HQs, registraram critérios elaborados por eles, além dos propostos pelos professores, para direcionarem o trabalho, já que deveriam considerar a faixa etária para a qual as HQs estavam sendo preparadas. Com base nisso, uma série de aspectos referentes à adequação do conteúdo para o público alvo foi demonstrada pelos grupos. Um deles, o qual trabalhou considerando os anos iniciais do Ensino Fundamental, que compreende idades de 7 a 10 anos geralmente, fez as seguintes considerações "o fato de nesta idade as crianças ainda estarem desenvolvendo suas habilidades na leitura, foi necessário que a história fosse criada com uma linguagem simples e fácil para que os alunos fossem capazes de entender. A busca por mais imagens do que falas dos personagens é outro aspecto adequado, já que os textos em forma de imagem são mais compreensíveis do que em forma de palavras. Além disso, tivemos a preocupação em aplicar conteúdos presentes no dia a dia das crianças, no caso da mãe fritando batata frita, espécie de comida muito apreciada pelas crianças. Por fim, acreditamos que esta história em quadrinhos irá sanar as dúvidas dos alunos das alfas, fazendo com que eles compreendam o que é correto e o que não é recomendável de fazer no descarte do óleo de cozinha e soluções para o reaproveitamento deste poluente que está presente em alguns desastres ambientais". Este cuidado pedagógico com o que estava sendo elaborado foi identificado como um ponto positivo expressado pelos alunos, demonstrando o envolvimento destes com a proposta.

Em algumas etapas da atividade, observou-se que a atividade não ocorreu de forma conjunta nos grupos. Porém, no momento de usar o programa Pixton, observouse mobilização e colaboração entre os integrantes, para um melhor entendimento das ferramentas disponíveis. Cabe ressaltar que a maioria dos alunos, manifestou-se positivamente em relação ao uso da ferramenta digital, com justificativas, tais como: "facilitou a produção das HQs"; "acelerou o trabalho"; "o uso da ferramenta é interessante"; "a ferramenta facilitou a comunicação entre os alunos".

Este trabalho com HQs indica que as TICs podem ser uma boa ferramenta para o desenvolvimento de práticas pedagógica interdisciplinares, propiciando um ambiente instigante e desafiador para professor e aluno. Além disso, a atividade desenvolvida corrobora a Lei de Diretrizes e Bases da Educação Nacional - LDBEN/96 e a Resolução CNE/98, que propõem que os currículos escolares do Ensino Médio devem oportunizar, além dos conteúdos específicos organizados por séries, situações-que possibilitem ao aluno compreender as tecnologias contemporâneas associando as mesmas aos conhecimentos científicos e aos problemas que estes se propõem a solucionar; relacionar princípios científicos e tecnológicos à sua vida, ao seu trabalho e ao desenvolvimento do conhecimento e das sociedades" (Brasil, 1998).

\section{Conclusão}


O fato de este trabalho ter sido desenvolvido com alunos do último ano do Ensino Médio, pode ter influenciado a identificação da atividade como algo sem utilidade para eles (vide comentários citados), uma vez que estes alunos não associaram o que foi proposto à preparação para o vestibular - com o que estavam mais preocupados no momento - o que gerou desmotivação para um comprometimento efetivo com a atividade. Entendemos este problema como uma limitação em perceber a quantidade de conceitos e habilidades que estavam sendo trabalhadas na produção das HQs, o que seria importante não somente para o vestibular mas também para outras situações que os estudantes encontrarão no seu dia-a-dia.

Entretanto, com base nos comentários dos alunos, incluindo aqueles que estavam mais resistentes ao desenvolvimento da proposta com as HQs, este trabalho mostrou-se desafiador e estimulou a interação entre os estudantes, além de ter problematizado os conteúdos trabalhados, o que possibilitou aos sujeitos atuarem como protagonistas da sua aprendizagem e reforçou a ideia de que o uso das TICs promove colaboração no processo de aprendizagem (Pais, 2002) e propicia novos espaços de construção de conhecimentos.

O processo pelo qual os alunos foram submetidos, desde a escrita do roteiro da história, até a finalização do trabalho, mostrou-se de grande importância para a discussão do tema bem como para que os estudantes pudessem se apropriar dos conhecimentos científicos relacionados ao assunto que estavam trabalhando.

Além disso, o produto final desta atividade pode ser utilizado pelos demais alunos na escola, com a distribuição das HQs para leitura, atingindo assim, o objetivo da socialização de informações, podendo ser apropriadamente aplicado na divulgação científica.

\section{Referências Bibliográficas}

BRASIL. Ministério da Educação. Diretrizes curriculares nacionais para o Ensino Médio. Parecer CEB 15/98. 01/06/98. Brasília, 1998.

CABELLO, K. A. S.; Rocque, L. L.; Sousa, I. C. F. Uma história em quadrinhos para o ensino e divulgação da hanseníase. Revista Electrónica de Enseñanza de las Ciencias Vol. 9, $\mathrm{N}^{\circ}$ 1, 2010. 225-241p.

CASTILHOS, W. Tiras científicas. Disponível em http://agencia.fapesp.br/8502, desde 03/04/2008. Acesso em: 15/05/2012.

DEMO, Pedro. Professor/Conhecimento. UnB, 2001. Disponível em:〈www.enap.gov.br/downloads/ec43ea4fProfessor_Conhecimento.pdf>. Acesso em: 16 agosto 2012.

GIRON, L. A. A dublagem venceu as lengendas. Revista Época. Ed. Globo. Disponível em: <http://revistaepoca.globo.com/cultura/noticia/2012/06/dublagem-venceulegendas.html >. Acesso em: 25 junho 2012.

INSTITUTO PRÓ-LIVRO. $3^{\mathrm{a}}$ edição da pesquisa Retratos da Leitura no Brasil. Divulgado em 28 de março de 2012. Disponível em <http://www.prolivro.org.br/ipl/publier4.0/texto.asp?id=2834>. Acesso em: 14 junho 2012.

MIRANDA, L.C.; Assis, R.; Martins, M. C.; Baranauskas, M. C. C.. Interdisciplinaridade via Laptop da OLPC Experimentada com Alunos do Ensino Fundamental. In: XXII SIMPÓSIO BRASILEIRO DE INFORMÁTICA NA EDUCAÇÃO - XVII WORKSHOP DE INFORMÁTICA NA ESCOLA. 2011.

MORAES, R. Análise de Conteúdo. Revista Educação, Porto Alegre, v. 22, n. 37, p. 7 32, 1999. 
MORAN, J. M. Ensino e aprendizagem inovadores com tecnologias audiovisuais e telemáticas. In: NOVAS TECNOLOGIAS E MEDIAÇÃO PEDAGÓGICA. Campina: Papirus, 2000.

NETO, J. C.; Bernardelli, M. S.; Pessoa, M. P.; Guilhem, M. S.; Malucelli, A.; Reinehr, S. O uso das TIC na formação de professores de escolas que obtiveram baixo IDEB. In: XXII SIMPÓSIO BRASILEIRO DE INFORMÁTICA NA EDUCAÇÃO XVII WORKSHOP DE INFORMÁTICA NA ESCOLA. 2011

PAIS, L. C. Educação Escolar e as Tecnologias da Informática. Belo Horizonte: Autêntica, 2002. 166p.

PIZARRO, M. V. As histórias em quadrinhos como linguagem e recurso didático no ensino de ciências. VII ENPEC - Encontro Nacional de Pesquisadores em Educação em Ciências. 2009.

RAMOS, P. Quadrinhos viram livro escolar em 2007. Blog dos quadrinhos Disponível em:< http://blogdosquadrinhos2.blog.uol.com.br/noticia/arch2006-11-01_2006-1130.html>. Acesso em: 30 abril 2012.

SANTOS, R. E. A História em Quadrinhos na Sala de Aula. INTERCOM - Sociedade Brasileira de Estudos Interdisciplinares da Comunicação. XXVI Congresso Brasileiro de Ciências da Comunicação. Belo Horizonte, MG. 2 a 6 Set 2003.

VERGUEIRO, W. C. S.; RAMA, Â. Como usar as histórias em quadrinhos em sala de aula. São Paulo: Contexto, v. 1. 2004. 157 p.

WILSON, R. E. Uso de Lógica Difusa na Avaliação de Aprendizagem Multidisciplinar. In: XXII SIMPÓSIO BRASILEIRO DE INFORMÁTICA NA EDUCAÇÃO XVII WORKSHOP DE INFORMÁTICA NA ESCOLA. 2011 